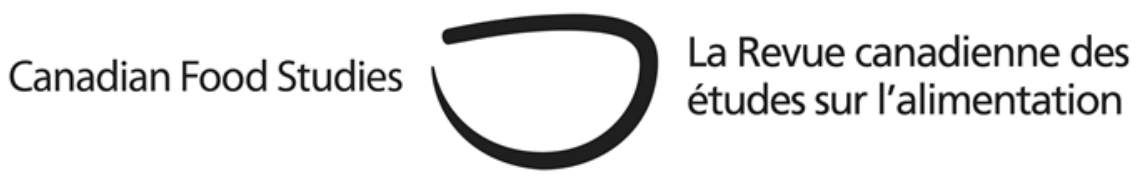

\title{
Editorial
}

\section{FLEdGE (Food: Locally Embedded, Globally Engaged) Partnership}

Alison Blay-Palmer

Wilfred Laurier University

The Food: Locally Embedded, Globally Engaged (FLEdGE) SSHRC-funded Partnership has deep roots in relationships developed over time among academics and community-based practitioners. FLEdGE emerged from community-driven research in Ontario on food hubs and community resilience dating from 2010. From there it expanded to include seven research nodes across Canada and three thematic international working groups, with over 90 researchers, students, and community partners involved in the project. As a multi-institutional project, FLEdGE has nodes in British Columbia (Kwantlen Polytechnic University)/Alberta (University of Alberta), Northwest Territories (Wilfrid Laurier University), northern Ontario (Lakehead University), eastern Ontario (Carleton University), southern Ontario (Wilfrid Laurier University; University of Guelph; University of Waterloo); Quebec (McGill University; Dawson College); and Atlantic Canada (Dalhousie University; Carleton University). There are two or more lead researchers in each node, typically from different disciplines and several community partners in each node. In this way, FLEdGE branched out to include more than 90 partners and collaborators.

The nature of FLEdGE as a modular configuration of community-defined projects meant that each node engaged in different work that shared the common goal of building increasingly equitable and sustainable food systems.

FLEdGE was guided by our Good Food Principles. While the Good Food Principles were always an assumed part of the research, the lead researchers from each of the nodes came together in Montreal in 2018 to define the principles to guide the second half of the project. Given the distributed nature of FLEdGE - where nodes had the autonomy to define the work according to their community needs - the principles were a way to help us identify and better communicate the synergies and higher-level findings of this work. 
They are an evolving tool that help us to speak to the project in plain and accessible language. Extracted directly from our website with updated additions in bold, italicized text. They are defined by category as:

\section{Farmer Livelihoods}

We need to help the people who produce our food adapt to changing economies by co-creating new opportunities for training, accessing capital and land, and connecting with eaters.

\section{Food Access}

We need to work together with people along the values chain to make local, healthy, and culturally appropriate food more-accessible to everyone.

\section{Indigenous Foodways}

We need to support self-determination, land-back and Indigenous food sovereignty by safeguarding Traditional foodways that rely on the health of the land, biodiversity and intergenerational knowledge-sharing supported by scale-appropriate technologies, capacity, and infrastructure.

\section{Ecological Resilience}

We need to encourage agroecological farming because it supports diverse ecosystems and communities by regenerating and protecting the natural environment.

Food Policy

We need good food policy that creates the conditions for cross-cultural collaboration, respects and protects the right to food at all levels of government and reflects the needs of people including groups that are marginalized based on gender, class, race, age, ability and Indigeneity and their communities.

\section{Food Connects}

We support community-driven research as a way of connecting people and food from the unique foodscapes where they eat and live.

Building sustainable food communities for all people living in Canada. 
As noted through the additions, the Good Food Principles evolve to reflect food systems practice and theory (FLEdGE, 2021: np).

As we share what we have learned in the final stages of the project, our focus has shifted to knowledge mobilization. Along with three edited volumes and many peer-reviewed papers, a key achievement is the podcast series, 'Handpicked: Stories from the Field', which has featured the voices of several FLEdGE researchers and will continue to feature FLEdGE work beyond the end of the project. One of the interesting things about FLEdGE is that, while the project was highly productive in terms of publications (including those published by and with students and community partners) we have also hosted several webinars (on the Good Food Principles) and large in-person meetings and created tools and resources that are publicly accessible on our website. To reflect the story of the project and capture all of that work so that it remains in the public domain, we are building a comprehensive online archive that will be accessible beyond the life of the project - to be maintained by the Laurier Centre for Sustainable Food Systems. As we imagine and build the FLEdGE archive, the Good Food Principles will help us organize and tell the story of FLEdGE research outputs.

This Special Issue - along with the Special Issue on the Social Economy — are vital contributions as they draw on and bring together many of the goals and research projects closely or loosely connected to FLEdGE. Thanks to the many contributors, and Alyson Jaagumagi Holland and the amazing Canadian Food Studies team, for making this Special Issue possible.

\section{Overview of papers}

In total there are nine papers in this themed section that capture various features of the Good Food Principles. It begins with Lowitt, a Perspective paper that connects food policy and food access. Titled 'Linking fisheries policy to sustainable diets: The case of Lake Superior', this paper centres fisheries as important sites of local food security. By applying a sustainable diets lens to fisheries on Lake Superior, the author provides insights into how policy can be more supportive.

In the second paper by Levkoe, Blay-Palmer, Knezevic, Szanto and Addy, titled 'Modularity in intersectoral research/action collaborations for food systems transformation: Lessons from the FLEdGE community-engaged network', we learn about ways that the FLEdGE network fostered food connections and some of the limitations throughout its tenure. Using a Social Network Analysis of FLEdGE, the authors found that in addition to adding to theory and practice, FLEdGE contributed to food movements in Canada and beyond. Through a modular approach, research nodes operated both independently while also sharing commonalities that fostered reconfigurations in flexible and fluid ways founded in interdisciplinarity, collaborative methodologies, and critical reflexivity. 
The third paper 'Mapping food policy groups: Understanding cross-sectoral network building through social network analysis' by Levkoe, Schiff, Arnold, Wilkinson, and Kerk assesses the extent to which the Thunder Bay and Area Food Strategy - as an example of a Food Policy Group - was able to integrate approaches to food policy, programs and planning. Using Social Network Analysis, their results suggest that this type of analysis both improves how we understand networks and supports cross-sectoral integration.

The fourth paper 'Meaning a motivator to address distancing in the food system' by Rideout uses research in India and Canada to explore food as important to relationships, soulful connections, and the sense of interconnectivity between all things. In turn, this evokes an awareness of bigger issues, a predisposition for an ethic of care, that leads to action or change. These findings are especially relevant as an opportunity to use the intrinsic value of food to inform public health policies. Both these papers look at food as a connector and an enabler of change.

The next two papers provide insights into Indigenous foodways and partnerships. In the first paper in this theme 'Moving your body, soul, and heart to share and harvest food': Food systems education for youth and Indigenous food sovereignty in Garden Hill First Nation, Manitoba authors Michnik, Thompson and Beardy propose an Indigenous food education programme grounded in traditional and spiritual beliefs, land-based learning, and selfdetermination. Insights based on their interviews with young adults, Elders, community food educators and Knowledge Keepers guide their recommendations on how to support communitybased, Indigenous food systems, including sovereignty. Supportive policies are needed that include how technology effects culture, the need for financial stability in northern and remote communities, and gender equality, while the educational programmes themselves need to be defined in their communities and focused on practice. The second paper, 'Working for justice in food systems on stolen land? Interrogating food movements confronting settler colonialism' by Bohunikcy, Levkoe and Rose, three settler activist-scholars, questions whether/how settler-led social movements are being accountable in working towards social and ecological justice on stolen land. Using comparative research interviews with settler-led food movement organizations in Northwestern Ontario and Southern Australia, they propose a continuum for food movements to deepen their engagements to confront settler colonialism that can move food systems towards more genuinely equitable and sustainable food systems.

The following paper by Roszko and Beckie, 'Growing with Lady Flower Gardens: Governance in a land-based initiative focused on building community, well-being and social equity through food' focuses our attention on how a privately owned community garden grapples with inclusiveness, social equity, and affordability. Through this case study of Lady Flower Gardens in Edmonton, they demonstrate the growth and change in approach and governance using the Policy Arrangement Approach. Through capacity-building with marginalized and disadvantaged community members, food is grown both for personal and community consumption improving food access, ecological resilience, and improved farmer livelihoods. The paper by André, Ballamingie and Coulas, presents in-depth findings into the Food Policy for 
Canada as an example of public policy to address food and nutrition-related health challenges. The paper concludes that while progress has been made, an integrative systems-based approach to problem-solving is still needed. The final paper also explores policy, this time in Montreal where Aunio and Dubé apply design-based implementation research to understand three different food policy collaborative city initiatives and the challenges they face as they strive to address food insecurity in their communities. The research demonstrates the role that historical pathways, old and new norms, path dependency, structures, capacity and international engagement in shaping policy and planning.

This themed section provides an opportunity to reflect on and question the Good Food Principles, the co-evolution of the food landscape in Canada and accompanying research. We are extremely grateful to all our amazing community partners and the students who made this work possible.

Acknowledgements: Nii Addy, Peter André, Anna-Liisa Aunio, Patricia Ballamingie, Mary Beckie, Alison Blay-Palmer, Mary Coulas, Amanda Di Battista, Laurette Dubé, Irena Knezevic, Karen Landman, Charles Levkoe, Catherine Mah, Phil Mount, Kent Mullinix, Connie Nelson, Erin Nelson, Heather Reid, Theresa Schumilas, Kelly Skinner, Andrew Spring, David Szanto, and Laine Young.

Funder acknowledgement: We are grateful to the Social Sciences Humanities Research Council (SSHRC) of Canada for its outstanding support for our work through its Partnership Grant 895-2015-1016.) 